\title{
Rapid pacing during aortic valve interventions: Review of pacing options and experience from Split
}

\section{-Frane Runjić, \\ -Andrija Matetić* -lvica Kristić, ONikola Crnčević}

University Hospital Centre Split, Split, Croatia
RECEIVED:

July 31, 2021

ACCEPTED:

August 5, 2021

回-

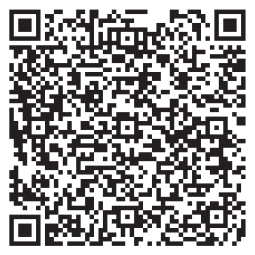

$\square$ Cardiologia Croatica 2021;16(9-10):298.
KEYWORDS: rapid pacing, aortic valve interventions, transcatheter aortic valve implantation. CITATION: Cardiol Croat. 2021;16(9-10):298-9. | https://doi.org/10.15836/ccar2021.298

*ADDRESS FOR CORRESPONDENCE: Andrija Matetić, Klinički bolnički centar Split, Spinčićeva 1, HR-21000 Split, Croatia. / Phone: +385-98-954-6455 / E-mail: andrija.matetic@gmail.com

ORCID: Frane Runjić, https://orcid.org/0000-0001-6639-5971 • Andrija Matetić, https://orcid.org/0000-0001-9272-6906 Ivica Kristić, https://orcid.org/0000-0002-9882-9145 • Nikola Crnčević, https://orcid.org/0000-0002-1399-3406

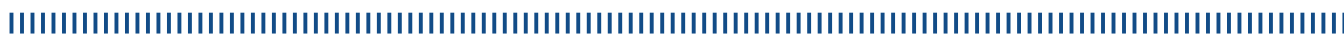

Background: Rapid pacing during balloon aortic valvuloplasty (BAV) or transcatheter aortic valve replacement (TAVR) is an important step allowing for proper valve position and effective implantation while avoiding valve pop-up or ventricular complications. There are different regimes for rapid pacing during BAV/TAVR, some of which will be presented here ${ }^{1}$

Materials and methods: Literature database PubMed has been reviewed yielding a total of 49 research articles related to rapid pacing during BAV/TAVR in the period of 2009 to 2021. Collected articles were assessed and reappraised to extrapolate different pacing options.

Literature overview: Rapid pacing during BAV/TAVR can be achieved by insertion of a temporary transvenous pacemaker, reprogramming the existing permanent pacemaker in situ, or over-the-wire (OTW) pacing ${ }^{1}$ (Figure 1). The latter further includes different protocols. The most utilized OTW pacing protocol is based on the pacing circuit consisting of a positive pole attached to the wire in the left ventricle (isolated with the catheter), while a negative pole is attached to the femoral subcutaneous tissue over the needle. However, while the described protocol offers an attractive and simple set-up, it carries a risk of contact loss, inadequate pacing, or possibly insufficient post-implantation pacing ${ }^{2}$. Therefore, we present our modification of the OTW pacing scheme which allows for a safer procedure and bail-out options if necessary (Figure 1). Contrary to the conventional OTW scheme, our protocol includes the attachment of a negative pole to a wire in the inferior vein cava (5 French femoral sheath). This allows for stable contact, adequate length of the negative electrode, and quick bail-out insertion of a temporary transvenous pacemaker if necessary.

Conclusions: Rapid pacing during BAV/TAVR is an important procedural step, and different methods have been described to achieve this. Modification of the existing protocol may lead to additional benefits and a more convenient procedure. 


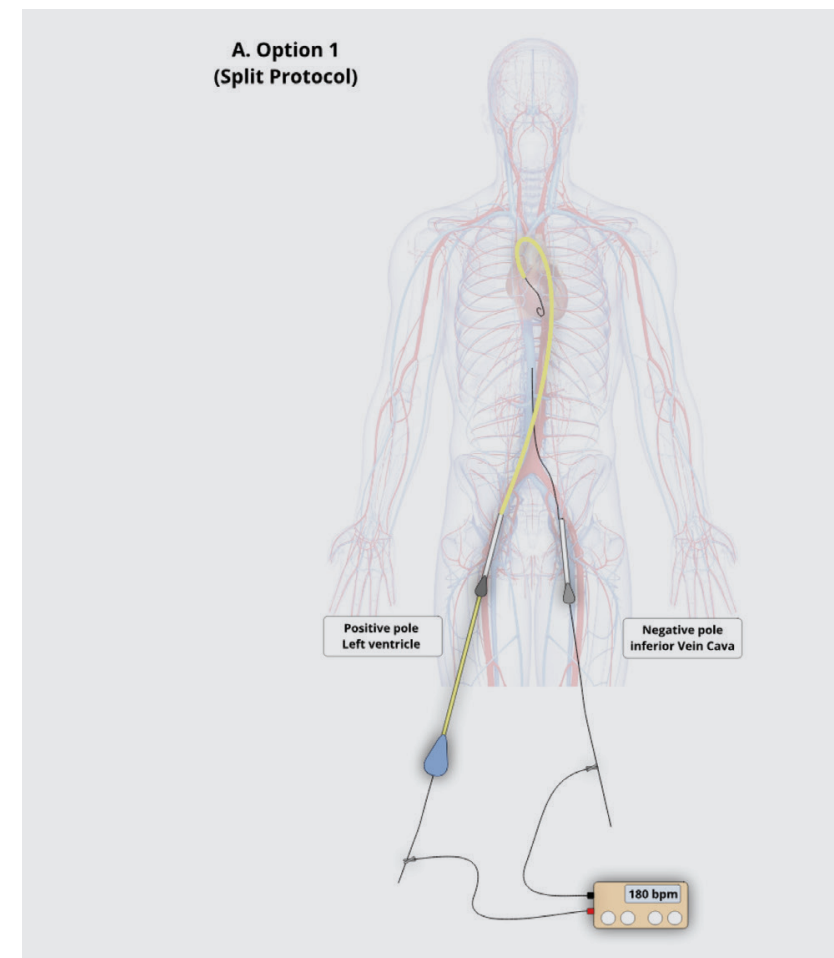

B. Option 2

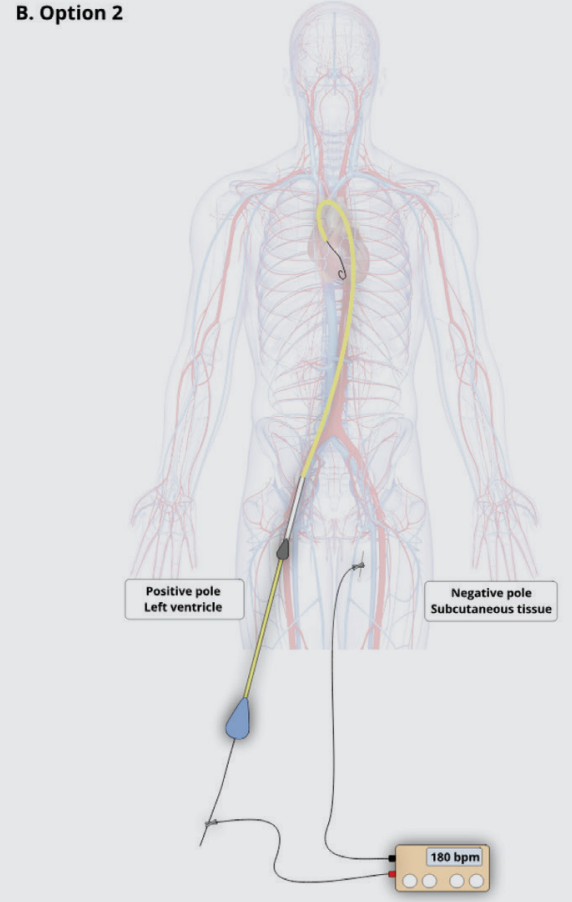

C. Option 3

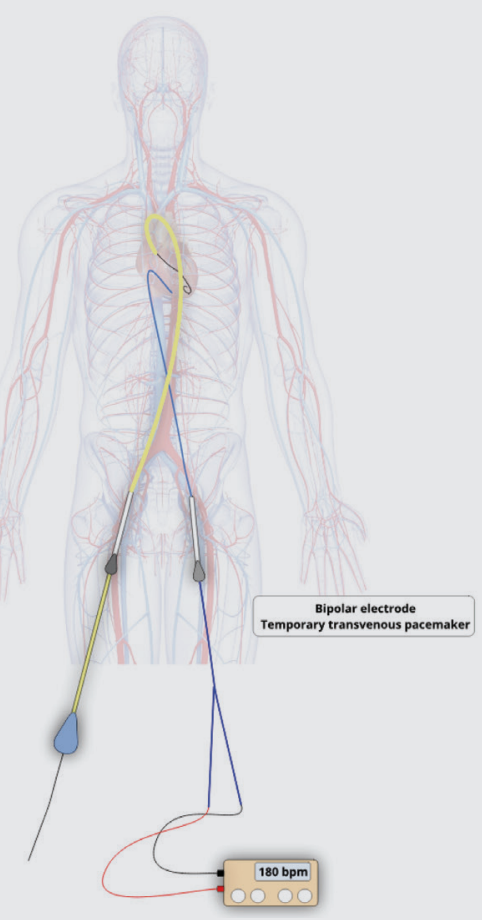

D. Option 4

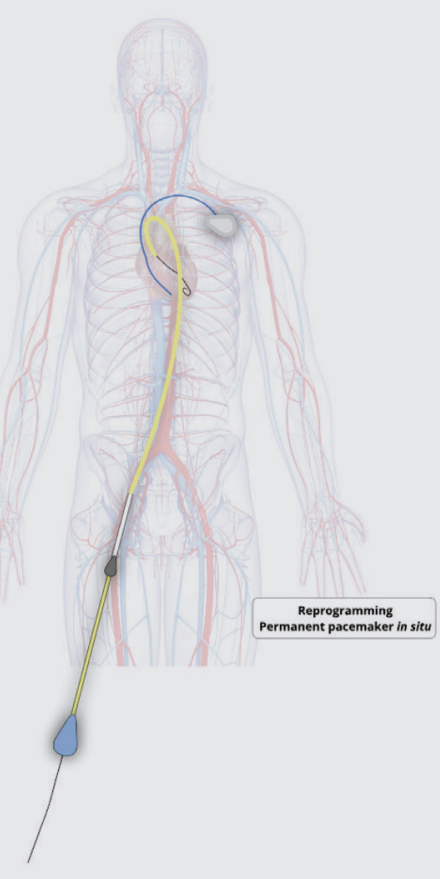

FIGURE 1. Illustrative overview of rapid pacing methods during balloon aortic valvuloplasty or transcatheter aortic valve replacement.

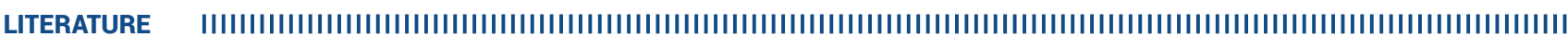

1. Akodad M, Lefèvre T. TAVI: Simplification Is the Ultimate Sophistication. Front Cardiovasc Med. $2018 \mathrm{Jul}$ 18:5:96. https://doi.org/10.3389/fcvm.2018.00096

2. Faurie B, Souteyrand G, Staat P, Godin M, Caussin C, Van Belle E, et al; EASY TAVI Investigators. Left Ventricular Rapid Pacing Via the Valve Delivery Guidewire in Transcatheter Aortic Valve Replacement. JACC Cardiovasc Interv. 2019 Dec 23;12(24):2449-2459. https://doi.org/10.1016/j.jcin.2019.09.029 